\title{
Inhibitive Characteristics of Cefalexin Drug Addition on Corrosion Evolution of Mild Steel in a Chloride Medium
}

\author{
O.S.I. Fayomi, ${ }^{1,4, *}$ I.G.Akande, ${ }^{2}$ D. Daramola,${ }^{3}$ G.A.Oluwadare, ${ }^{3}$ API Popoola ${ }^{4}$ \\ ${ }^{1}$ Department of Mechanical Engineering, Covenant University, Ota, Ogun state, Nigeria \\ ${ }^{2}$ Department of Mechanical Engineering, University of Ibadan, Ibadan, Oyo state, Nigeria \\ ${ }^{3}$ Department of Mechanical and Biomedical Engineering, Bells University of Technology, Ota, \\ Ogun State, Nigeria. \\ ${ }^{4}$ Department of Chemical, Metallurgical and Materials Engineering, Tshwane University of \\ Technology, Pretoria, South Africa. \\ *Corresponding author: ojo.fayomi@covenantuniversity.edu.ng
}

Received 06/08/2018; accepted 05/11/2020

https://doi.org/10.4152/pea.202102149

\begin{abstract}
The inhibition effect of Cefalexin on mild steel corrosion in sodium chloride has been examined with the use of electrochemical potentiodynamic polarization techniques, weight loss measurements and computational studies. Cefalexin showed good protection ability by adsorbing onto the mild steel surface. The mixed inhibition characteristics of Cefalexin were revealed by the potentiodynamic polarization results. The inhibitor efficiency was found to be above $65 \%$, obeying the Langmuir and Freundlich isotherm law, with a correlation regression coefficient of $\mathrm{R}^{2}=0.9984$ and $\mathrm{R}^{2}=0.9488$, respectively, establishing the reliability on Cefalexin as an inhibitor.
\end{abstract}

Keywords: Mild steel, polarization, interfaces, passivation and Cefalexin.

\section{Introduction}

Corrosion is one of the most devastating occurrences in modern technology, and poses a serious threat to many industries. Corrosion is destructive to mild steel ${ }^{1-3}$. It is a crucial and costly problem in industries. It represents a considerably large proportion of loss, as a result of lost production, inefficient operation and high maintenance ${ }^{4,5}$. Hence, corrosion control is of paramount importance to scientists and engineers. The studies on steel corrosion phenomena have become an industrial and academic topic, especially on acidic and saline media, in recent years $^{6-8}$. Several organic, as well as inorganic inhibitors, have been used to provide protection for metals, but quite often, these compounds can be potentially toxic, very costly, difficult to isolate and characterize from their natural sources ${ }^{9-11}$. For these reasons, recent researches have been directed towards inhibitive drugs. One of the most practical methods through which mild steel is protected against corrosion is the use of inhibitive drugs or organic inhibitors, which are becoming more and more popular, considering the recent studies $^{12-16}$. The effectiveness of organic molecules is a function of their ability to 
adhere to the metal surface, which can distinctly alter the corrosion mitigating properties of mild steel ${ }^{17}$. This has assumed great significance, due to their application in preventing corrosion under different corrosive environments ${ }^{18-21}$. The use of drug inhibitors draws much attention, due to their high efficiency, easiness of synthesis and cost-effective nature. They show good corrosion protection and are highly environment-friendly ${ }^{22}$.

Drug inhibitors adsorption onto the steel surface forms a protective coating that restricts diffusion of chemical species involved in steel ionization. Numerous active drug components have been identified to be potent for mild steel protection, in different corrosive environments ${ }^{23,24}$. In most cases, expired drugs can be tested as corrosion inhibitors, and steel degrades only in an infinitesimal way $^{25,26}$. This research aimed at examining the inhibitive ability of Cefalexin on mild steel corrosion in a seawater simulated environment (sodium chloride solution). The effect of Cefalexin, on the corrosion behaviour of mild steel, was observed using linear polarisation techniques, weight loss measurements and computational studies. Most antibiotics and their decomposition products possess electron donor groups that can bind naturally occurring metal ions, thereby forming complexes with them.

\section{Experimental procedures}

Sample preparation

Table 1. Chemical composition of a mild steel sample.

\begin{tabular}{lcccccccc} 
Element & $\mathrm{C}$ & $\mathrm{Mn}$ & $\mathrm{Si}$ & $\mathrm{P}$ & $\mathrm{Al}$ & $\mathrm{S}$ & $\mathrm{Ni}$ & $\mathrm{Fe}$ \\
$\mathrm{Wt} \%$ & 0.15 & 0.45 & 0.18 & 0.01 & 0.005 & 0.031 & 0.008 & 99.166 \\
\hline
\end{tabular}

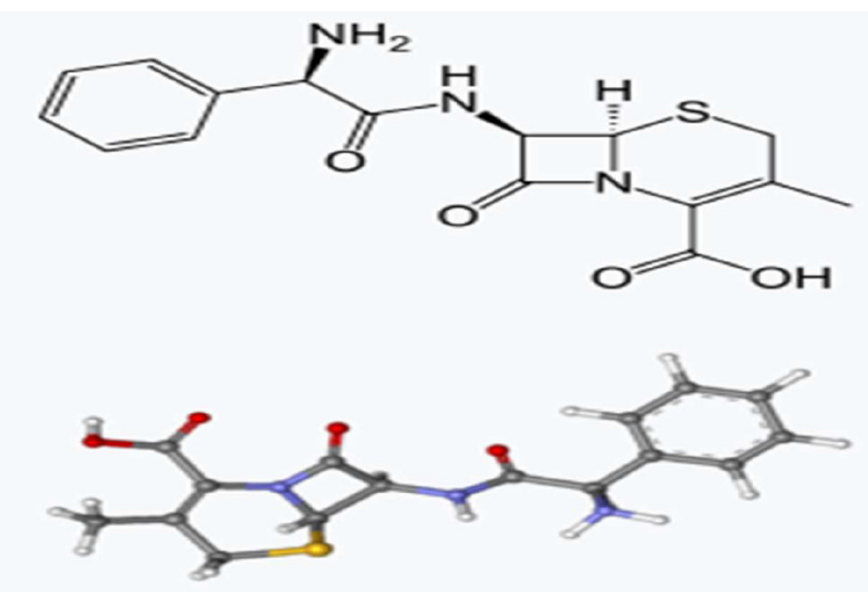

Figure 1. Structure of Cefalexin ${ }^{27}$.

The mild steel coupons used for these studies had the dimensions of $15 \times 10 \times 2$ $\mathrm{mm}$, with a $2 \mathrm{~mm}$ diameter hole drilled at the centre top of the samples. The spectrometer chemical composition in wt \% is shown in Table 1.

These coupons were then polished with emery papers of different grades, and each specimens weight was recorded and labelled appropriately. The mild steel 
specimens were placed in a sodium chloride $(3.65 \% \mathrm{NaCl})$ solution of $200 \mathrm{~mL}$, in plastic containers with inhibitors at concentrations of $0 \%, 10 \%, 30 \%, 50 \%$ and $100 \%$, and they were monitored over a period of 21 days. The molecular structure of the prepared inhibitor is shown in Fig. 1, and its molecular mass is $347.389 \mathrm{~g} / \mathrm{mol}$. The electrochemical investigation was performed at ambient temperature.

\section{Linear polarization Resistance}

An Autolab PGSTAT 101 Metrohm potentiostat/galvanostat, connected to a computer, was used to obtain linear polarization measurements. The mild steel coupon was welded to a wire and mounted on a resin. Steel acted as working electrode. A graphite rod was used as counter electrode, and a silver chloride electrode (SCE) functioned as reference electrode. Linear potentiodynamic potential scan range was from $-1.5 \mathrm{~V}$ to $+1.5 \mathrm{mV}$, at a scan rate of $0.0016 \mathrm{mV} / \mathrm{s}$. The polarization potential ( $\mathrm{E}_{\text {corr }}$ ), and current density ( $\left.\mathrm{I}_{\text {corr }}\right)$ data were evaluated from the Tafel plots. The surface coverage $(\theta)$ and the percentage inhibition efficiency (\% IE) were calculated with equation 1 and $2^{28}$.

$$
\Theta=1-\frac{\text { Icorr }}{\text { Iocorr }}
$$

The percentage inhibition efficiency (\% IE) was calculated from corrosion current density values using equation $2^{29,30}$.

$$
\mathrm{I} . \mathrm{E} \%=1-\frac{\text { Icorr }}{\text { Iocorr }} X 100
$$

where $\mathrm{I}_{\text {corr }}$ is the inhibited corrosion current densities and $\mathrm{I}_{\text {ocorr }}$ is the uninhibited corrosion current density.

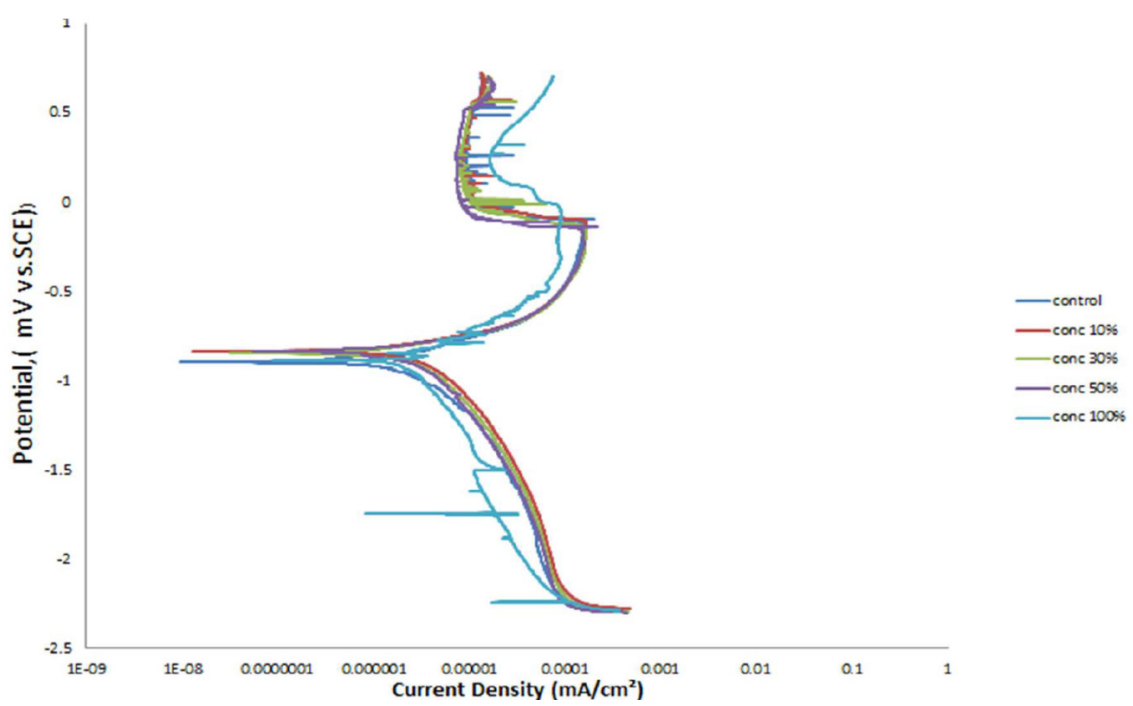

Figure 2. Potentiodynamic polarization curves for inhibited and uninhibited mild steel. 


\section{Results and discussion}

\section{Linear potentiodynamic polarization}

Mild steel potentiodynamic parameters in $3.65 \% \mathrm{NaCl}$, in the absence and presence of different inhibitor concentrations, are given in Table 2, and their corresponding polarization curves are shown in Fig. 2. This study revealed that the corrosion current density ( $\left.\mathrm{I}_{\text {corr }}\right)$ markedly decreased with the increase in the inhibitor concentration. However, the values of corrosion potential $\left(\mathrm{E}_{\text {corr }}\right)$ shifted slightly to less negative values, upon addition of Cefalexin, indicating that it behaved as a mixed-type inhibitor, but predominantly as an anodic inhibitor in a $\mathrm{NaCl}$ solution, adsorbing its molecules onto the mild steel surface ${ }^{29,31}$.

Table 2. Polarization parameters for inhibited and uninhibited mild steel.

\begin{tabular}{cccccc}
\hline Samples & C, Con & $\begin{array}{c}\text { CR } \\
(\mathrm{mm} / \mathrm{y})\end{array}$ & $\begin{array}{c}\text { Ecorr, Obs } \\
(\mathrm{V})\end{array}$ & $\begin{array}{c}\text { Icorr } \\
\left(\mathrm{A} / \mathrm{cm}^{2}\right)\end{array}$ & IE (\%) \\
\hline A & 0 & 0.051761 & -0.89058 & $4.45 \mathrm{E}-06$ & 0 \\
B & 10 & 0.021845 & -0.88595 & $1.88 \mathrm{E}-06$ & 55.78 \\
C & 30 & 0.020907 & -0.84566 & $1.80 \mathrm{E}-06$ & 59.55 \\
D & 50 & 0.019274 & -0.85501 & $1.66 \mathrm{E}-06$ & 62.70 \\
E & 100 & 0.017673 & -0.85305 & $1.52 \mathrm{E}-06$ & 65.84 \\
\hline
\end{tabular}

Weight loss measurements

Results gotten from weight loss measurements are shown graphically in Fig. 3. The result indicates that the introduction of Cefalexin into the corrosive medium caused a significant reduction in mild steel corrosion and wear ${ }^{32}$. However, the weight loss of the inhibited and uninhibited samples increased with time, but it was minimal for the inhibited samples. The minimal weight loss is as a result of the ability of Cefalexin to form an adhesive synergy on the metal surface, like some other antibiotics ${ }^{33}$.

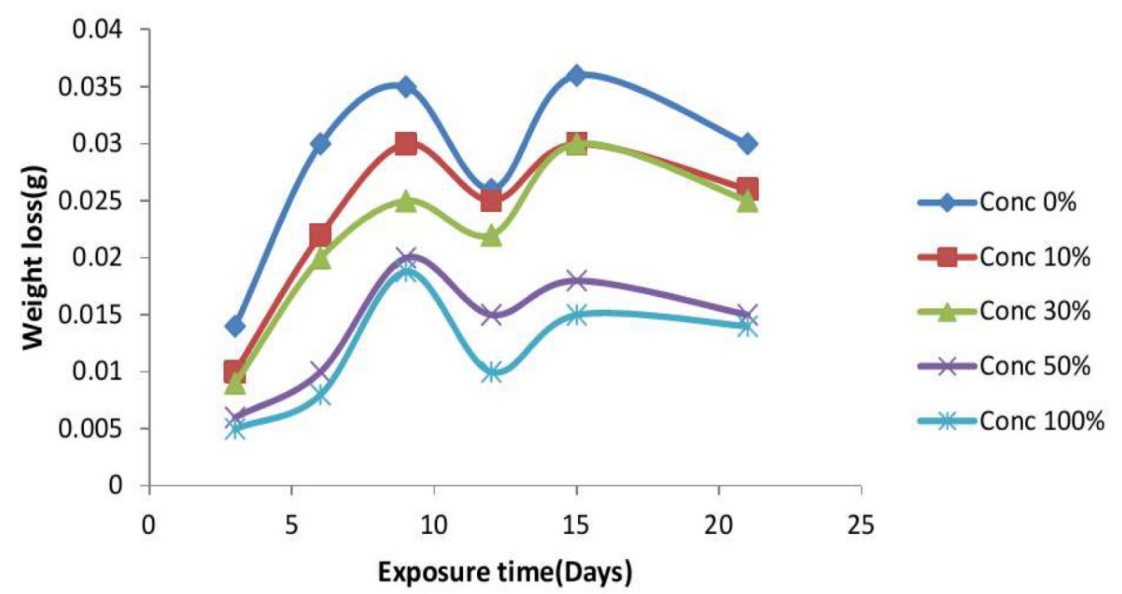

Figure 3. Variation of weight loss by the inhibited and uninhibited samples. 


\section{Mechanism of inhibition efficiency and adsorption study}

The values of corrosion current $\left(\mathrm{I}_{\text {corr }}\right)$ and corrosion rates $(\mathrm{CR})$ were found to reduce with an increase in Cefalexin concentration, as shown in Table 2, indicating its adsorbent characteristic onto the mild steel surface ${ }^{34}$. The corrosion inhibition efficiency of Cefalexin increases with an increase in concentration. In order to have a good knowledge of the metal-inhibitor interaction and the metallic-complex activities on the coverage site, an adsorption mechanism facilitated the computation of $\mathrm{C} / \theta$ and $\mathrm{C}$ for potentiodynamic polarization, using Langmuir isotherm and a linear relationship ${ }^{35,36}$. Equation (3) and (4) show the Langmuir and Freundlich isothermal, respectively. The Langmuir and Freundlich plots, in Fig. 4 and Fig. 5, on the surface features, show a linear relationship with the increase in the inhibitor concentration, indicating its continued adsorption onto the steel surface. The values of $\left(\mathrm{R}^{2}\right)$ for Langmuir and Freundlich are 0.9984 and 0.9488 , respectively, which are in accordance with the works of ${ }^{37,38}$. This shows that the mild steel corrosion protection by Cefalexin had been achieved, since $\mathrm{R}^{2}$ is close to unity.

The Langmuir isothermal law is ${ }^{38,39}$ :

$$
\frac{\mathrm{C}}{\theta}=\frac{1}{\mathrm{~K}_{\mathrm{ads}}}+\mathrm{C}
$$

The Freundlich isotherm law is ${ }^{40}$ :

$$
\log \theta=\log \mathrm{K}_{\mathrm{ads}}+\mathrm{n} \log \mathrm{C}
$$

where $\mathrm{C}$ is the concentration of the corrosion inhibitor, $\theta$ is the degree of surface coverage and $k$ is the adsorption equilibrium constant.

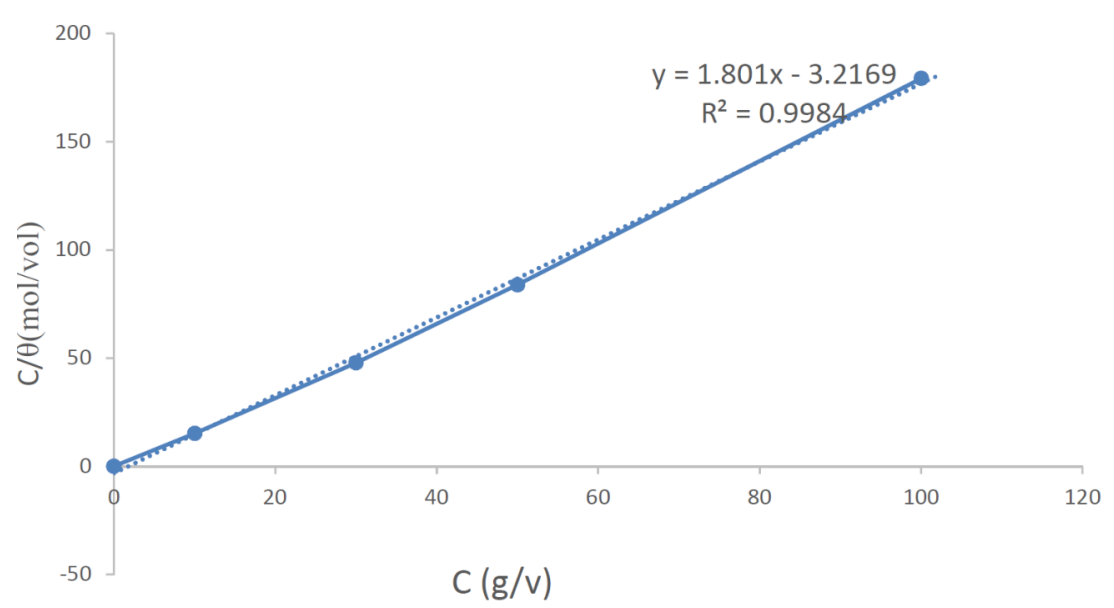

Figure 4. Langmuir adsorption isotherm of inhibited mild steel, at room temperature. 


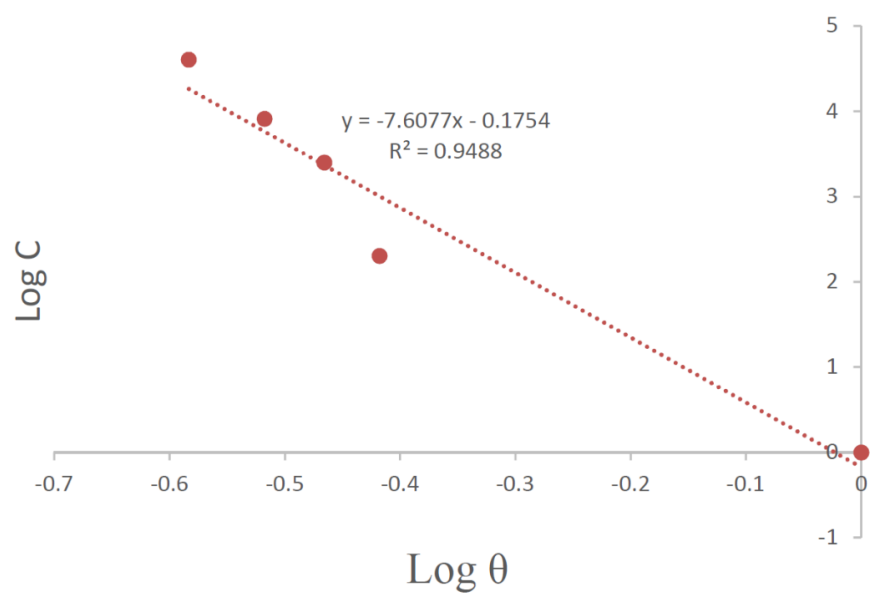

Figure 5. Freundlich isotherm of inhibited mild steel, at room temperature.

\section{Conclusions}

1. Langmuir isotherm and Freundlich isotherm law were obeyed by the inhibitor, with a correlation regression coefficient of $\mathrm{R}^{2}=0.9984$ and $\mathrm{R}^{2}=0.9488$. The values of $\mathrm{R}^{2}$ are near unity, indicating the effectiveness of the inhibitor.

2. Maximum corrosion inhibition efficiency of $65.84 \%$ was obtained for the inhibited mild steel in a salt solution. There is a tendency of further increment in inhibition efficiency, if the concentration of Cefalexin is increased.

3. The polarization studies showed that Cefalexin acted as a mixed-type inhibitor. This is an indication that the cathodic and anodic reactions were affected by the inhibitive drug. However, the anodic effect was predominant.

4. The corrosion of mild steel substrate in the chloride environment was mitigated by the effective adsorption of Cefalexin molecules.

\section{References}

1. Pathak RK, Mishra P. Drugs as corrosion inhibitors: a review. Int J Sci Research. 2016;5(4):671-7. Doi: https://doi.org/10.1016/j.corsci.2011.08.006

2. Popoola LT, Grema AS, Latinwo GK, et al. Corrosion problems during oil and gas production and its mitigation. Int J Ind Chem. 2013;4(1):35. Doi: https://doi.org/10.1186/2228-5547-4-35

3. Omotosho OA, Ajayi OO, Fayomi OS, et al. Assessing the deterioration behaviour of mild steel in $2 \mathrm{M}$ sulphuric acid using Bambusa glauscescens. Int J Appl Enginee Research, Dindigul. 2011;2(2):406-18.

4. Karthik G, Sundaravadivelu M. Studies on the inhibition of mild steel corrosion in hydrochloric acid solution by atenolol drug. Egyptian J Petroleum. 2016;25(2):183-91. Doi: https://doi.org/10.1016/j.ejpe.2015.04.003

5. Raja PB, Qureshi AK, Rahim AA, et al. Neolamarckia cadamba alkaloids as eco-friendly corrosion inhibitors for mild steel in $1 \mathrm{M} \mathrm{HCl}$ media. Corros Sci. 2013;69:292-301. Doi: https://doi.org/10.1016/j.corsci.2012.11.042

6. Zaferani SH, Sharifi M, Zaarei D, et al. Application of eco-friendly products as corrosion inhibitors for metals in acid pickling processes-A review. J 
Environm Chem Eng. 2013;1(4):652-7. Doi: https://doi.org/10.1016/j.jece.2013.09.019

7. Golestani G, Shahidi M, Ghazanfari D. Electrochemical evaluation of antibacterial drugs as environment-friendly inhibitors for corrosion of carbon steel in $\mathrm{HCl}$ solution. Appl Surf Sci. 2014;308:347-62. Doi: https://doi.org/10.1016/j.apsusc.2014.04.172

8. Golestani G, Shahidi M, Ghazanfari D. Electrochemical evaluation of antibacterial drugs as environment-friendly inhibitors for corrosion of carbon steel in $\mathrm{HCl}$ solution. Appl Surf Sci. 2014;308:347-62. Doi: https://doi.org/10.1016/j.apsusc.2014.04.172

9. Ofoegbu SU, Ofoegbu PU. Corrosion inhibition of mild steel in $0.1 \mathrm{M}$ hydrochloric acid media by chloroquine diphosphate. ARPN J Eng Appl Sci. 2012;7(3):272-6.

10. Kumar H, Karthikeyan S. Inhibition of mild steel corrosion in hydrochloric acid solution by cloxacillin drug. J Mater Environmen Sci. 2012;3(5):925-34.

11. Edison TN, Atchudan R, Pugazhendhi A, et al. Corrosion inhibition performance of spermidine on mild steel in acid media. J Mol Liq. 2018;264:483-9. Doi: https://doi.org/10.1016/j.molliq.2018.05.087

12. Gece G. Drugs: A review of promising novel corrosion inhibitors. Corros Sci. 2011;53(12):3873-98. Doi: https://doi.org/10.1016/j.corsci.2011.08.006

13. Shukla SK, Quraishi MA. Cefalexin drug: A new and efficient corrosion inhibitor for mild steel in hydrochloric acid solution. Mat Chem Phys. 2010;120(1):142-7. Doi: https://doi.org/10.1016/j.matchemphys.2009.10.037

14. Obot IB, Obi-Egbedi NO, Umoren SA, et al. Antifungal drugs as corrosion inhibitors for aluminium in 0.1 M HCl. Corros Sci. 2009;51(8):1868-75. Doi: https://doi.org/10.1016/j.corsci.2009.05.017

15. Shukla SK, Singh AK, Ahamad I, et al. Streptomycin: A commercially available drug as a corrosion inhibitor for mild steel in hydrochloric acid solution. Mat Letters. 2009;63(9-10):819-22. Doi: https://doi.org/10.1016/j.matlet.2009.01.020

16. Fouda AS, Mostafa HA, El-Abbasy HM. Antibacterial drugs as inhibitors for the corrosion of stainless steel type 304 in $\mathrm{HCl}$ solution. J Appl Electrochem. 2010;40(1):163-73. Doi: https://doi.org/10.1007/s10800-009-9992-1

17. Solmaz R. Investigation of corrosion inhibition mechanism and stability of Vitamin B1 on mild steel in 0.5 M HCl solution. Corros Sci. 2014;81:75-84. Doi: https://doi.org/10.1016/j.corsci.2013.12.006

18. Daoud D, Douadi T, Issaadi S, et al. Adsorption and corrosion inhibition of new synthesized thiophene Schiff base on mild steel X52 in $\mathrm{HCl}$ and $\mathrm{H} 2 \mathrm{SO} 4$ solutions. Corros Sci. 2014;79:50-8. Doi: https://doi.org/10.1016/j.corsci.2013.10.025

19. Dahiya S, Lata S, Kumar R, et al. Comparative performance of Uroniums for controlling corrosion of steel with methodical mechanism of inhibition in acidic medium: Part1. J Mol Liq. 2016;221:124-32. Doi: https://doi.org/10.1016/j.molliq.2016.05.073 
20. Hari Kumar S, Karthikeyan S. Torsemide and furosemide as green inhibitors for the corrosion of mild steel in hydrochloric acid medium. Ind Eng Chem Research. 2013;52(22):7457-69. Doi: https://doi.org/10.1021/ie400815w

21. Terrones VB, Campos CM, Romo MR, et al. Electrochemical evaluation of an outdated antifungal drug as corrosion inhibitor of mild steel in neutral chloride media. Innov Corros Mater Sci. 2015;5(1):31-5. Doi: https://doi.org/10.2174/2352094905666150622183729

22. Verma C, Ebenso EE, Bahadur I, et al. 5-(Phenylthio)-3H-pyrrole-4carbonitriles as effective corrosion inhibitors for mild steel in $1 \mathrm{M} \mathrm{HCl}$ : Experimental and theoretical investigation. J Mol Liq. 2015;212:209-18. Doi: https://doi.org/10.1016/j.molliq.2015.09.009

23. Vaszilcsin N, Ordodi V, Borza A. Corrosion inhibitors from expired drugs. Int J Pharmac. 2012;431(1-2):241-4. Doi: https://doi.org/10.1016/j.ijpharm.2012.04.015

24. Rotaru I, Varvara S, Gaina L, et al. Antibacterial drugs as corrosion inhibitors for bronze surfaces in acidic solutions. Appl Surf Sci. 2014 Dec 1;321:188-96. Doi: https://doi.org/10.1016/j.apsusc.2014.09.201

25. Nazeer AA, El-Abbasy HM, Fouda AS. Antibacterial drugs as environmentally-friendly corrosion inhibitors for carbon steel in acid medium. Res Chem Intermed. 2013;39(3):921-39. Doi: https://doi.org/10.1007/s11164-012-0605-y

26. Singh P, Chauhan DS, Srivastava K, et al. Expired atorvastatin drug as corrosion inhibitor for mild steel in hydrochloric acid solution. Int J Ind Chem. 2017;8(4):363-72. Doi: https://doi.org/10.1007/s40090-017-0120-5

27. Akpan IA, Offiong NO. Electrochemical and gravimetric studies of the corrosion inhibition of mild steel in $\mathrm{HCl}$ medium by cephalexin drug. Am J Chem and Mat Sci. 2014;1(1):1-6.

28. Haque J, Verma C, Srivastava V, et al. Experimental and quantum chemical studies of functionalized tetrahydropyridines as corrosion inhibitors for mild steel in $1 \mathrm{M}$ hydrochloric acid. Results Phys. 2018;9:1481-93. Doi: https://doi.org/10.1016/j.rinp.2018.04.069

29. Fayomi OS, Atayero AA, Mubiaye P, et al. Mechanical and opto-electrical response of embedded smart composite coating produced via electrodeposition technique for embedded system in defence application. $\mathbf{J}$ Alloys Compd. 2018; 773:305-33. Doi: https://doi.org/10.1016/j.jallcom.2018.09.191

30. Anejjar A, El Mouden OI, Batah A, et al. Corrosion Inhibition Potential of Ascorbic acid on Carbon Steel in Acid Media. Appl J Env Eng Sci.2017;3(1):36-46.

31. Fouda AS, Mahmoud WM, Mageed HA. Evaluation of an expired nontoxic amlodipine besylate drug as a corrosion inhibitor for low-carbon steel in hydrochloric acid solutions. J Bi Tribo-Corros. 2016;2(2):7.

32. Chitra S, Anand B. Surface morphological and FTIR spectroscopic information on the corrosion inhibition of drugs on mild steel in chloride environment. J Chem Pharm Sci. 2017;10:453-6. 
33. Akpan IA, Offiong NA. Inhibition of mild steel corrosion in hydrochloric acid solution by Ciprofloxacin drug. Int J Corr. 2013; 301689. Doi: https://doi.org/10.1155/2013/301689

34. Niouri W, Zerga B, Sfaira M, et al. Electrochemical and Chemical Studies of some Benzodiazepine Molecules as Corrosion Inhibitors for Mild Steel in 1 M HCl. Int J Electrochem Sci. 2014;9(9):8283-98.

35. Fayomi OS, Abdulwahab M, Durodola BM, et al. Study of the electrochemical behavior and surface interaction of AA6063 Type Al-Mg-Si alloy by sodium molybdate in simulated seawater environment. Int J Manag, Inf Tech Eng. 2013;1(3):159-66.

36. Fayomi OS, Popoola AP. The Inhibitory Effect and Adsorption Mechanism of Roasted Elaeis guineensis as Green Inhibitor on the Corrosion Process of Extruded AA6063 Al-Mg-Si Alloy in Simulated Solution. Silicon. 2014;6(2):137-43. Doi: https://doi.org/10.1007/s12633-014-9177-3

37. Fayomi OSI, Akande IG, Popoola API. Corrosion Protection Effect of Chitosan on the Performance Characteristics of A6063 Alloy. J Bio TriboCorros. 2018;4:73. Doi: https://doi.org/10.1007/s40735-018-0192-6

38. Hameed RA, Al-Shafey HI, Abu-Nawwas AH. 2-(2, 6- dichloroaniline) phenylacetic acid Drugs as Eco-Friendly Corrosion Inhibitors for Mild Steel in 1M HCl. Int J Electrochem Sci. 2014;9:6006-19.

39. Fouda AS, Ibrahim H, Rashwaan S, et al. Expired Drug (pantoprazole sodium) as a Corrosion Inhibitor for High Carbon Steel in Hydrochloric Acid Solution. Int J Electrochem Sci. 2018;13:6327-46. Doi: https://doi.org/10.20964/2018.07.33

40. Foo KY, Hameed BH. Insights into the modeling of adsorption isotherm systems. Chem Eng J. 2010;156(1):2-10. Doi: https://doi.org/10.1016/j.cej.2009.09.013 